\title{
A Study On Alcohol Use Among The College Students
}

\author{
Dr. K. Maheswari* and Ms.R.Maheswari** \\ *Head, Department of Social Work, Bharathidasan University College, Perambalur. \\ **Ph.D Scholar, Department of Social Work, Bharathidasan University College, Perambalur.
}

\begin{abstract}
Alcoholism is a complex disease, which has been misunderstood and stigmatized. According to the American medical association "Alcoholism" is an illness characterized by significant impairment that is directly associated with persistent and excessive use of alcohol. Impairment may involve physiological, psychological or social dysfunction. The two major types of alcohol use disorders are alcohol abuse (problem drinking) and alcohol dependence (alcoholism).Alcohol abuse is an unhealthy pattern of excessive drinking that can lead to alcohol dependence. People who abuse alcohol drink too much or too frequently, but they are not yet physically addicted to alcohol. Nowadays alcohol consumption has become a status symbol and mostly youngsters use it for fun which in turn becomes addiction. The main aim of the study is to analyze the alcohol use among college students studying at Bharathidasan University Constituent College, Perambalur. The researcher has adopted simple random sampling method to select the sample of boy students. The sample size is 61. The researcher has used descriptive research design for the study. The major findings of the study revealed that majority of the respondents have the habit of drinking alcohol and less than half of the respondents (41\%) feel guilt and remorse for the same.
\end{abstract}

Key words: Alcohol, college, snow ball sampling, Perambalur

\section{INTRODUCTION}

College students in many countries are at elevated risk for heavy drinking, with serious immediate health risks, such as drink-driving and other substance use; and longer term risks, such as alcohol dependence. Many of these young students will be exposed, during this transitional period, to substantial changes in living arrangements, socialization groups, and social activities. This kind of transition is often associated with risky behaviour such as excessive alcohol consumption. Alcoholism is also known as alcohol use disorder (AUD) and alcohol dependence syndrome, is a broad term for any drinking of alcohol that results in problem, (Littrell,(2014). It was previously divided into two types: alcohol abuse and alcohol dependence. (Hasin and Deborah, 2003). In a medical context alcoholism is said to exist when two or more of the following is present: a person drinks large amounts over a long time period, has difficulty cutting down, acquiring and drinking alcohol takes up a great deal of time, alcohol is strongly desired, usage results in not fulfilling responsibilities, usage results in social problems, usage results in health problems, usage results in risky situations, withdrawal occurs when stopping, and alcohol tolerance has occurred with use. Alcohol use can affect all parts of the body but particularly affects the brain, heart, liver, pancreas, and immune system. This can result in mentalillness, Drinking during pregnancy can cause damage to the baby resulting in fetal alcohol spectrum disorders. Generally women are more sensitive to alcohol's harmful physical and mental effects than men. (Global status report on alcohol and health, 2014). Both environmental factors and genetics are involved in causing alcoholism with about half the risk attributed to each. A person with a parent or sibling with alcoholism are three to four times more likely to be alcoholic themselves. Environmental factors include social, cultural, and behavioral influences. (Kozlowski and Agarwal, 2000) High stress levels, anxiety, as well as inexpensive easily accessible alcohol increases risk. (Moonat and Pandey, 2012). People may continue to drink partly to prevent or improve symptoms of withdrawal. A low level of withdrawal may last for months following stopping. Medically alcoholism is considered both a physical and mental illness. (Mersy,2003). College drinking is the consumption of alcohol by students on the campus of any college or university. The age at which it is legal to drink varies by country and affects whether college drinking is considered illegal Binge drinking occurs when students drink large amounts of alcohol in a relatively short space of time in order to feel the full effects of alcohol consumption. There are many health hazards that are caused from drinking. When students drink too much, the alcohol affects one's brain and ability to comprehend what is going on. One such problem is alcohol poisoning. After drinking too much, the alcohol and toxins in alcoholic drinks cause complications in one's brain and respiratory system. This causes mental and physical issues in one's body and could be very dangerous for one's health. This is a toxic drug that could potentially be slipped into one's drink which cause one to lose sight of what one thinks and does. 


\section{REVIEW OF LITERATURE}

Johnston et al (2002) has conducted a study on epidemiology of alcohol and other drug use among American college students. Five different sources of data are examined for estimating recent levels of alcohol (and other drug) use among college students: Harvard school of public health college alcohol study, the core institute, monitoring the future, national college health risk behavior survey and national household survey on drug abuse. The findings of the study revealed that alcohol use rates are very high among college students. Alcohol use is higher among male than female students. White students are highest in heavy drinking, black students are lowest and hispanic students are intermediate. Longitudinal data show that, while in high school, students who go on to attend college have lower rates of heavy drinking than do those who will not attend college. Both groups increase their heavy drinking after high school graduation, but the college students increase distinctly more and actually surpass their nonstudent age-mates. Loran et al (2013) have studied the alcohol drinking among college students: college responsibility for personal troubles. So far, however, there is little evidence about the social determinants of alcohol consumption among college students. In May 2010 a web questionnaire was sent to all bachelor and master students registered with an important Belgian university; 7,015 students participated The survey looked at drinking behaviour, social involvement, college environmental factors, drinking norms, and positive drinking consequences. It was found that the more a student was exposed to college environmental factors, the greater the risk of heavy, frequent, and abusive drinking. Alcohol consumption increased for students living on campus, living in a dormitory with a higher number of roommates, and having been in the University for a long spell. Most such environmental factors were explained by social involvement, such as participation to the student folklore, pre-partying, and normative expectations. Educational and college authorities need to acknowledge universities' responsibility in relation to their students' drinking behaviour and to commit themselves to support an environment of responsible drinking. Hill et al (2013) have conducted a study on self-esteem and alcohol-related negative consequences among college student drinkers. These two types of self-esteem were studied to determine their effects on alcohol use in a sample of 623 college students. Zeigler-Hill classified secure self-esteem participants as those with consistent and general high levels of self-esteem. Participants with secure and fragile self-esteem reported their alcohol consumption behaviors and consequences and these results were compared to those of students with low self-esteem. ZeiglerHill found that the students with fragile self-esteem had similar drinking patterns and consequences as those with low self-esteem. Overall, even though the fragile self-esteem individuals did have higher self-esteem with respect to some domains, the contingencies they placed on their self-esteem created pressures that caused them to be more vulnerable to stress. This has led to negative coping strategies, such as increased alcohol use.

\section{RESEARCH METHODOLOGY}

Aim

The aim of the study is to analyze the alcohol use among the college male students studying in Bharathidasan University Constituent College at Perambalur district.

\section{Objectives of the study}

$>$ To study the socio-demographic characteristics of the respondents.

$>$ To assess the level of alcohol use by the respondents.

$>$ To find out the association between the selected socio demographic variables and Key variable.

$>$ To suggest suitable measures to enhance the responsibility and functioning of the college students.

\section{Universe and Sampling}

The graduate students studying in Bharathidasan University Constituent College, perambalur constituted the population of the study. The universe of the study comprises of 610 male students and from this 10 per cent of the male students having the habit of drinking was selected for the study. Simple random sampling method was adopted and the sample size is 61 . Descriptive research design was used for this study.

\section{METHOD}

A semi-structured interview schedule was used to find out the views of respondents regarding the alcohol use and its frequency, behavior and changes in their life due to addiction. These respondents were interviewed individually inside the campus. In addition, the researcher was able to explain the question to the respondents; if they had any problem in understanding. For analyzing the data, the researcher has used quantitative method and findings were discussed in detail. 
Profile of the respondents

\section{RESULTS AND DISCUSSIONS}

The socio demographic characteristics of the respondents are presented below; More than half of the male respondents $(55.7 \%)$ are in the age group of 21 to 23 years and all are unmarried. It is also evident that majority of the respondents $(75.4 \%)$ are living in rural areas and great majority of the respondents $(93.4 \%)$ belong to Hindu religion. All the respondents are in III year and majority of them $(62.3 \%)$ are dependent on their parents income for their expenses and 38.7 per cent are doing part time jobs. It is also clear that little more than half of the respondents (50.8\%) family income is between Rs. 15001 to 20000 and great majority of the respondents (93.4\%) are not having two-wheeler. As an impact of transition of joint family system, great majority of the respondents $(91.8 \%)$ are with nuclear families. Regarding the family size of the respondents, little more than half of the respondents family size $(52.5 \%)$ comprises maximum of four members. It is also evident from the study that, majority of the respondents $(73.8 \%)$ have assets and are living in their own houses, with facilities such as electricity (100\%), water sources $(96.7 \%)$ and more than half of the respondents $(57.4 \%)$ do not have toilet facilities in their house and this is because majority of the respondents come from rural areas with agricultural background and do open defecation. It is also clear that majority of the respondents $(83.6 \%)$ family members have the habit of saving and it is done through banks. Though they have saving habit, great majority of the respondents have said that they have financial problem to deal with big expenses. It is noted from the research study that little less than half of the respondents $(44.3 \%)$ are taking alcohol monthly once or twice and their regular drink is beer (59\%). It is very shocking to know that 39.3 per cent need their first drink in the morning itself and little less than half of the respondents $(45.9 \%)$ are able to remember what happened in the night. The respondents have also said that $(41 \%)$ they have the feeling of guilt and remorse. It is also revealed from the study that nearly half of the respondents $(52.5 \%)$ have said that they have quarreled and injured others as a result of their drinking. Majority of the respondents (75.4\%) have said that they have not tried to stop the habit of drinking. It was also found that there is a significant difference between the domicile of the respondents and their habit of drinking alcohol and a significant association has been found between the age and alcohol use and this is due to the peers influence and their part time jobs. It is also observed from this study that there is a significant negative correlation between income of the respondents and alcohol use. As income increases the alcohol use among the college students also increases.

\section{Suggestions}

$>$ Awareness on alcoholism and its ill - effects must be given to the college students.

$>$ Behaviour modification and attitudinal changes can be brought by giving training programme to the students.

Importance of family relationship must be stressed upon to lead a peaceful living.

$>$ The youngsters must understand their roles and responsibilities and must be self reliant

$>$ Life skill education must be introduced in the syllabus of all disciplines.

\section{CONCLUSION}

We as a society have moral function and surely emerged as a better place to live in, but they must not forget the values that our forefathers left behind for us. It is a sad reflection that the younger generation are portraying a negative side and the society, family loses hope on them. They are the pillars of our nation and the younger generations must understand their roles and responsibility as a human being and must avoid this life threatening habit to lead a healthy and peaceful life.

\section{REFRENCESE}

[1] Association, American Psychiatric (2013).Diagnostic and statistical manual of mental disorders : DSM5. (5 ed.). Washington, D.C.: American Psychiatric Association. pp. 490-497. ISBN 9780890425541.

[2] Global status report on alcohol and health 2014 (PDF). World Health Organization. 2014. p. s8,51.ISBN 9789240692763.

[3] Jill Littrell (2014). Understanding and Treating Alcoholism Volume I: An Empirically Based Clinician's Handbook for the Treatment of Alcoholism:volume Ii: Biological, Psychological, and Social Aspects of Alcohol Consumption and Abuse. Hoboken: Taylor and Francis. p. 55.ISBN 9781317783145.

[4] Patrick, M. O’Malley, Ph.d., Lloyd D. Johnston, Ph.d. Epidemiology of Alcohol and Other Drug Use among American College Students. Institute for Social Research, Survey Research Center, Room 2320, University of Michigan, P.O. Box 1248, Ann Arbor, Michigan 48106-1248

[5] Pedersen, Eric; LaBrie, Josephy; Kilmer, Jason (June 2009). "Before You Slip in to the Night, You'll Want Something to Drink: Exploring the Reasons for Prepartying Behavior Among College Student Drinkers". Issues in Mental Health Nursing 30 (6): 354363. doi:10.1080/01612840802422623. PMID 19499435. Retrieved 20 October 2011. 
[6] Mersy, D.J. (1 April 2003). "Recognition of alcohol and substance abuse.". American family physician 67 (7): 1529-32. PMID 12722853.

[7] Moonat, S; Pandey, S.C. (2012). "Stress, epigenetics, and alcoholism.". Alcohol research : current reviews 34 (4): 495-505. PMID 23584115.

[8] Agarwal-Kozlowski K, Agarwal, D.P. (April 2000). "[Genetic predisposition for alcoholism]". Ther Umsch 57 (4): 179-84.doi:10.1024/0040-5930.57.4.179. PMID 10804873. 